\title{
Intradiploic Epidermoid Cyst of the Frontal Bone Presenting with Tension Pneumocephalus*
}

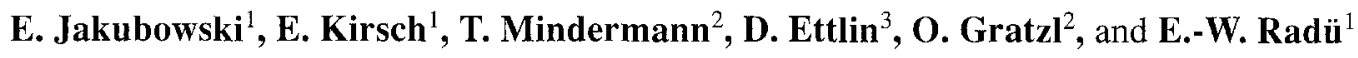 \\ ${ }^{1}$ Division of Neuroradiology, Department of Radiology, ${ }^{2}$ Division of Neurosurgery, Department of Surgery, and ${ }^{3}$ Division of Reconstruc- \\ tive Surgery, Department of Surgery, University of Basel, Switzerland
}

\section{Introduction}

Intradiploic manifestations of epidermoid tumours are benign, slow-expanding and of small or moderate size [3]. Increasing to larger size, diploic epidermoids can cause focal neurological signs and intracranial hypertension [4].

We report on the second case of an intradiploic epidermoid cyst resulting in neurological deficits caused by tension pneumocephalus.

\section{Case Report}

A 52-year-old female was admitted with a history of depressive character alteration and progressive forgetfulness. Neurological examination revealed a moderate left-sided hemiparesis and anisocoric pupils with a dilated pupil on the right side reactive to light in a conscious and fully orientated patient.

Plain X-ray films of the skull demonstrated a frontal lesion consisting of a giant mass of intracranial frontal air and a well-delineated lytic calvarial lesion without sclerotic margins (figure). Contrast-enhanced computed tomography (CT) showed destruction of the skull at the level of the frontal sinus due to a diploic tumour of parenchymal-like density. The tumour indicated a communication with the right-sided frontal pneumocephalus leading to compression of the right frontal lobe and the right ventricle (Fig. 1). Bone setting windows showed erosion of the outer and inner table of the calvarium.

Bifrontal craniotomy revealed a mostly intradiploic tumour invading the frontal sinus, displacing the frontal lobes and showing dural adherence. The tumour was completely resected with excision of frontal dura (TM) and reconstruction of the skuIl (DE). The postoperative course was uneventful and the hemiparesis resolved.

Histologically there was no evidence of malignancy in this diploic epidermoid cyst.

* Keywords: Epidermoid cyst; diploic cyst; tension pneumocephalus; computerized tomography.

\section{Discussion}

Unique feature of this case is the spontaneous development of a tension pneumocephalus with leftsided hemiparesis and anisocoric pupils. It was caused by a large intradiploic epidermoid cyst of the frontal bones with erosion of the frontal sinus and the internal table leading to a valve mechanism with the entrapment of air intracranially.

Diploic epidermoid cysts expanding in an intracranial direction have been reported to cause intracranial hypertension, convulsions or focal neurological signs $[3,4]$. To our best knowledge, our case of an intradiploic epidermoid cyst is the second case reported to present with intracranial hypertension and neurological deficit caused by pneumocephalus [2].

Findings in plain X-ray films of the skull and CT are acknowledged to give correct diagnosis for intradiploic epidermoid cysts preoperatively. Plain X-ray films usually show well-defined lytic lesions of the skull with sclerotic margins, predominantly located in the parietal or frontal bones [5]. On CT, simultaneous erosion of inner and outer table of the skull is reported to occur in up to 72 percent of cases with diploic epidermoids [5]. They represent soft masses of low density or of parenchymal-like density [5], showing dural infiltration in $10 \%$ of reported cases [1]. Apart from sclerotic margins our case demonstrates the classical radiological findings of an intradiploic epidermoid cyst, showing involvement of the inner and outer table of the skull. Pneumocephalus is an extraordinary feature which was present in this rare case of diploic epidermoid cyst of the frontal bone. 

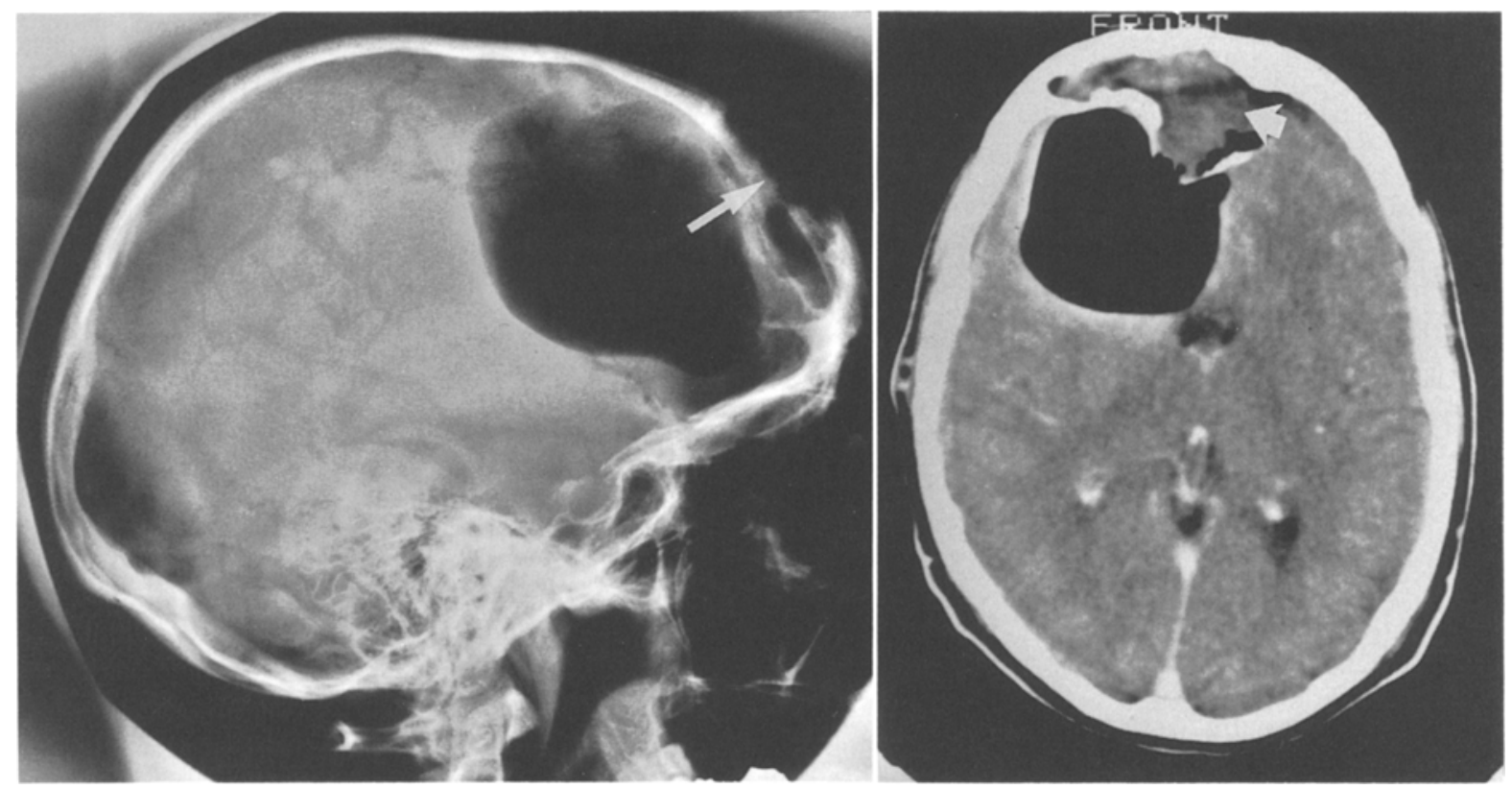

Fig. 1. Plain X-ray film of the skull in lateral view reveals a lytic lesion extending above the frontal sinus (arrow) and intracranial air (left). Contrast-enhanced computed tomography (CT) demonstrates diploic neoplasm (thick arrow) and right-sighted pneumocephalus leading to compression of the frontal parenchyma and frontal horns of the lateral ventricles (right)

\section{References}

1. Boyko OB, Scott JA, Muller J (1994) Intradiploic epidermoid cyst of the skull: case report. Neuroradiology 36: 226-227

2. Clark JB, Six EG (1984) Epidermoid tumor presenting as a tension pneumocephalus. Case report. J Neurosurg 60: 1312-1314

3. Constans JP, Meder JF, De Divitiis E, et al (1985) Giant intradiploic cysts of the skull. Report of two cases. J Neurosurg 62: 445-448

4. Ciappetta P, Artico M, Salvati M, Raco A, Gagliardi FM (1990) Intradiploic epidermoid cysts of the skull: report of 10 cases and review of the literature. Acta Neurochir (Wien) 102: 33-37

5. Arana E, Latorre FF, Revert A, Menor F, Riesgo P, Liano F, Diaz C (1996) Intradiploic epidermoid cysts. Neuroradiology 38: $306-311$

Correspondence: E. Kirsch, M.D., Division of Neuroradiology, Department of Radiology, University Hospital, Petersgraben 4, CH-4031 Basel, Switzerland. 